Article

\title{
Female Entrepreneurship in Perspective: A Methodological Issue
}

\author{
Paola Paoloni ${ }^{1}$ (D) and Gabriele Serafini ${ }^{2, *}$ \\ 1 Department of Law and Economics of productive activities, Sapienza Università di Roma, 00185 Rome, Italy; \\ paola.paoloni11@gmail.com \\ 2 Department of Economics and Business, Niccolò Cusano University, 00133 Rome, Italy \\ * Correspondence: gabriele.serafini@unicusano.it
}

Received: 23 August 2018; Accepted: 30 October 2018; Published: 3 November 2018

check for updates

\begin{abstract}
A methodological approach to the concept of female entrepreneurship concept has not yet been treated: is female entrepreneurship an individual or collective concept? Is it considered a social or natural variable? The purpose of this research is to clear up these alternatives, which are preparatory questions for any research into female entrepreneurship that wishes to measure its features and effects. The article starts with the proposal of an identification procedure, necessary to identifying the variables of female entrepreneurship. It proceeds by classifying the concept of female entrepreneurship into four different modes and discussing their characteristics. The originality of this research consists in its fourfold classification of the concept of female entrepreneurship, intended as a preparatory step prior to the analysis of its characteristics and measures.
\end{abstract}

Keywords: female entrepreneurship; entrepreneurship; economic variable classification

\section{Introduction: The Identification of Female Entrepreneurship}

An analysis of the recent literature revealed methodological issues not yet treated regarding female entrepreneurship (Serafini 2018). It is, in fact, not yet clear whether female entrepreneurship is an individual or collective concept, or whether it is considered a social or natural variable. The first alternative deals with the problem that although entrepreneurship is, in the literature, considered an individual characteristic (Screpanti and Zamagni 2005) - even when its characteristics are related to, or depend on, macroeconomic variables (Parker 2018, p. 88) - the term female refers to a gender quality that is collective. The second alternative relates to the nature of entrepreneurship, since it can be considered an historically originated characteristic and a social creation (Bettio and Verashchagina 2008), or a feature that can be taken for granted because it remains qualitatively unchanged throughout time (Barker and Kuiper 2003), even if it changes quantitatively throughout time (Parker 2018, p. 451). The purpose of this article is to clear up these alternatives, which are preparatory questions for any research into the features of female entrepreneurship and their measurement. This is why the classification and definition of the concept of female entrepreneurship are related to individuation and the (eventual) measurement of its features, as it is not possible to study a variable independently of its classification and definition. Unfortunately, the classification and definition of the subject matter of a study is, in turn, not an undisputed issue in economic theory (Hausman 2008, p. 1), because "what is" an economic variable is strictly connected to the economic model and its theoretical assumptions, elaborated by the researcher who poses the question (Boniolo and Vidali 2003, pp. 31,35). It is then important to state the subject matter identification procedure of a variable, which includes its classification and definition as a first step, being aware that "there is a boundary between me and my objects only on a conscious, secondary process level of organization; on a primary process level, I am my objects and my objects and I are always, necessary, inseparable" 
(Mitchell 2014, p. 44). Only after having determined that an adequate identification procedure is essential to the measurement of its characteristics, will it be possible to deal with alternative possible classifications of the characteristic, which will be addressed in the next paragraph.

Since classification can be intended to mean the demarcation of the external environment with respect to the variable, the definition of the variable can be intended as the boundaries of the variable. In this way, classification matches an inward perspective from the exterior and definition matches an outward perspective from the interior, where both are affected by coexistent theoretical assumptions. This first step has to be followed by a second step, dedicated to the identification of the characteristics of the variable and their classification, definition and eventual measurement. The subject matter identification procedure can therefore be constituted by the two steps displayed in Table 1 .

Table 1. Subject matter identification procedure.

\begin{tabular}{cl}
\hline Step & Research Subject Matter \\
\hline 1 & Classification and definition: boundaries from exterior and interior. \\
2 & Characteristics: classifications, definitions, (eventual) measurement. \\
\hline
\end{tabular}

The two-step procedure can be a support when reasoning about the qualification of economic variables and their features, but in our specific case the only aim of the article is the classification and definition of the concept of female entrepreneurship. This is because the recent economic literature on female entrepreneurship directly focuses on characteristics, waiving the classification and definition step and revealing this lack of qualification. This is the consequence a fact that according to (Swedberg 2000, p. 7)) it is worth noting, namely that "most people who are not economists probably expect the economics literature to be full of analyses of entrepreneurship, since economics after all is the social science that deals most directly with contemporary economic reality. This, however, is not the case". Once the necessity of an identification procedure has been clarified, we should deal with the issue of its classification, in the knowledge that with regard to entrepreneurs and entrepreneurship, "there is no general agreement about the meaning of these terms" (Parker 2018, p. 6).

\section{Results: Two Alternatives and a Fourfold Qualification}

The term female relates to gender issues and collective characteristics but, in this context of economic variables, it is placed next to the term entrepreneurship, which is usually intended as an individual variable, even when collective variables influence its performance (Parker 2018, p. 300). By focusing on the name, we could thus perceive an oxymoron, but by means of a literature analysis we can state that research into female entrepreneurship has not yet investigated whether it is an individual or collective variable, and whether it has a social or natural derivation (Serafini 2018). This is why the nature and qualifications of the concept of female entrepreneurship has remained untapped until now, although the importance of the research into this concept has a dual meaning. (1) Since in the literature "entrepreneurship" is defined as a variable pertaining to individuals (see the following quotation), the concept female entrepreneurship suggests a collective qualification for this variable. The point is that in the recent literature about female entrepreneurship its collective character is not problematized. Screpanti and Zamagni (2005, pp. 181-82) say that in the modern economics model "the economy is made up of a plurality of agents who are present on the market either as consumers or as suppliers of productive services or as entrepreneurs [... ] Clearly, there is no place in this model for the notion of social class. On the contrary, there are just two groups of individuals: the consumers and the entrepreneurs, distinguished solely by the different decisions they are called upon to take." (2) In the recent literature on female entrepreneurship, gender differences between entrepreneurs are not investigated with regard to their social or natural origins. That is, it is not investigated whether the gender differences between female and male entrepreneurship are due to historical constructions or natural differences between the two sexes-if we can refer to the traditional two sexes, which are called to mind by the term female. These two points indicate why the methodological issue mentioned above 
is preparatory to any recognition and classification of the characteristics of female entrepreneurship and, as we will see in the next paragraph, these two mentioned alternatives produce four different classification modes. Only one of these corresponds to the traditional definition of entrepreneurship as an individual variable that evolves over time.

Since the economic literature, at least from the last decades of the nineteenth century, qualifies entrepreneurship from an individual rather than a collective point of view, reflection is needed in order to classify it as individual or collective. Joseph A. (Schumpeter 1991, p. 855)) wrote that, according to the economic paradigm, which has dominated since that period, "all social phenomena resolve themselves into decisions and actions of individuals that need not or cannot be further analyzed in terms of superindividual factors." Nowadays, on the contrary, it is necessary to clarify whether female entrepreneurship has a social or natural character. This is because, regardless of whether it is individual or collective, the qualification may be the result of social evolution, which has created the features of female entrepreneurship, or the result of natural sex differences. According to the social evolution hypothesis, both male and female entrepreneurs can have entrepreneurship characteristics and the label of male or female entrepreneurship depends on the gender of the individual having a certain quantity of these characteristics. This means that social evolution determines variations in these characteristics and their quantities, since the classification as male or female entrepreneurship is not connected with a person's birth sex. On the other hand, according to the natural character hypothesis of male or female entrepreneurship, male entrepreneurship cannot also have characteristics classified as female entrepreneurship because of their naturally different origin. From this perspective, birth determines the possibility and characterization of males and females. Table 2 at the end of this paragraph sets out the four cases.

In order to depict the importance of prior classification, we can refer to the classical problem of linking an economic variable with the consequences of its use. Only after the decision regarding the classification of female entrepreneurship has been made, will it be possible to establish typical male and female entrepreneurial characteristics. Only after having established these, will it be possible to understand the links between characteristics and value creation, i.e., correlation (pure or spurious) or causation. For example, only after having established female entrepreneurship as a collective variable will it be possible to exclude that differences in value creation between male and female entrepreneurs are due to individual differences, instead of gender. Table 2 presents the fourfold classification of the concept of female entrepreneurship, from which it emerges that if female entrepreneurship is a collective variable, it is considered a substitute for the entrepreneurship concept because it is not of an individual nature. At the same time, if female entrepreneurship is considered a natural variable, it is unchangeable over time and in different historical periods.

Table 2. Classification of female entrepreneurship (FE).

\begin{tabular}{ccc}
\hline & \multicolumn{1}{c}{ Individual } & Collective \\
\hline Social & $\begin{array}{c}\text { FE is the same concept } \\
\text { as entrepreneurship }\end{array}$ & $\begin{array}{c}\text { FE substitutes the individual concept and its } \\
\text { characteristics can be had by male entrepreneurs }\end{array}$ \\
\hline Natural & $\begin{array}{c}\text { FE is an omothetic concept with } \\
\text { respect to entrepreneurship }\end{array}$ & $\begin{array}{c}\text { FE substitutes the individual concept and its } \\
\text { characteristics cannot be had by male entrepreneurs }\end{array}$ \\
\hline
\end{tabular}

\section{Discussion. Individual Entrepreneur or Gender Variable}

The economic literature maintains that an entrepreneur combines productive factors and obtains profit because of her/his particular-not general-abilities, since she/he does not have a particular productive factor, and she/he is not an individual representing any social group. (Walras 2006, p. 319)) maintains that entrepreneur is the fourth role (alongside workers, capital owners and land owners) that combines productive factors. In this way, a multitude of independent agents acts in every economic system, with every agent trying to assert her/his capacity to profitably combine productive factors. 
According to the economic literature, value creation and capital enhancement depend on individual qualities rather than gender qualities.

While value creation has been studied in relation to female entrepreneurship, an entrepreneur's profit is implicitly considered the result of gender qualities and differences, not individual qualities and differences. This even hypothesizes individual differences depending on the different qualities of each entrepreneur, because this cannot invalidate the original common matrix of gender differences. This hypothesis underlies research into gender issues in business and economics. In this case, the qualification of female entrepreneurship as a social or natural variable becomes necessary, as in the economic literature there is no consensus on this issue. (Barker and Kuiper 2003, p. 1)), for example, indicate that feminist economics is "reconceptualizing what economics is". This is because the feminist point of view implies a different vision of economic categories, and gender difference takes on a different and natural meaning if the gender perspective is not recognized as being filtered through particular lenses. We think that the following quotation can be read in this way: "we intend to participate in moving feminist economics out of the margin and into the center: to become economics, unmodified" (ibidem). From this point of view, the feminist vision does not stand alongside a male-dominated vision and believes that it is a universal point of view. Therefore, when the concept of female entrepreneurship changes, it changes due to the affirmation of a more general point of view and gender differences are considered natural differences.

The book edited by Bettio and Verashchagina (2008) can be placed in contrast to this. According to these authors, gender questions have a social nature, that is, they depend on the historical factors that created them. Pat Hudson writes, "gender is a social rather than a biological construction, and it has a history" (Bettio and Verashchagina 2008, p. 21). As a social construction, female entrepreneurship is a variable with characteristics that can also be had by male entrepreneurs, even if to such an extent that they do not qualify them as female entrepreneurs. As a gender variable it is still a super-individual variable, but its collective nature has a definite historical connotation.

The importance of the qualification of the concept of female entrepreneurship in terms of one of the four proposed classifications is also closely linked to the consequences it has on the classification of linked economic variables and concepts. For example, it has consequences for the concept of competition, because a competitive market is typically populated by a myriad of individuals, each with different tastes and aims, whereas a standardized qualification of individuals changes the market features, definitions and functions. From a preliminary assessment of the nature of female entrepreneurship, we can infer that if it is considered a collective quality, then the concept of competition - which includes the economic situation characterized by the presence of a set of small businesses, each of which it is not able to influence fundamental economic magnitudes-cannot be scientifically defined as the limit towards which the economic system tends. This is because every economic system, according to this point of view, is not characterized by the presence of independent entrepreneurs, as they have autonomous characteristics and compete on markets due to their different aims. The economic system, on the contrary, is characterized by the presence of entrepreneurs who are classifiable into standard types. Therefore, the market would be populated by subjects who behave according to standard qualities that cancel the individual essence that characterizes an ideal entrepreneur, who can be described as independent of other entrepreneurs and consumers. Standard qualities and gender differences, rather than particular qualities and gender differences, limit the individual differences that characterize a competitive market. The essence of an entrepreneur, in this context, would no longer be individual, even if considering that each entrepreneur has the same characteristics as the others, but held in different quantities. This is because the essence of gender is what remains once individual particularities are neglected, which are neglected precisely because entrepreneurship is defined as a gender variable. It is necessary to completely understand this alternative: if female entrepreneurship is considered an individual quality, you cannot trace and measure it within gender-based research, whereas if it is considered a gender and standardized quality, you cannot explain the qualities of economic systems through individual entrepreneurs. 


\section{Methods: Qualification of Female Entrepreneurship and Measurement of its Limits}

This article has a methodological focus because it states, for the first time in the literature (Serafini 2018; Paoloni and Demartini 2016; Parker 2018), the inadequacy of the study of the characteristics and features of female entrepreneurship, which often proceeds without the premise of a statement about the nature of the variable female entrepreneurship. The literature has mainly focused on the differences between male and female entrepreneurship (Barker and Kuiper 2003, p. 145 ff), discrimination against female scholars (Madden 2002, p. 4 ff), or the measurement of the features of female entrepreneurship (Serafini 2016, p. 1919), but has not reflected on the possibilities of classifying the concept of female entrepreneurship.

This is why the framework of the article had a twofold purpose: (a) to clarify that it is not correct to study and measure a variable if it is not explicitly identified (Leti 1983; Bracalente et al. 2009); and (b) stimulate scholars to reflect on the nature of female entrepreneurship in order to make it distinctively measurable.

Due to the term "female", female entrepreneurship can be intended as a gender-based field of research, or research into the standardized qualities and functions of standardized human beings, rather than research into a particular function that characterizes individuals. This qualitative difference, moreover, distinguishes subsequent quantitative research, because it is preparatory to the possibility of measuring the research object; thus the research has a wider significance.

The two alternative determinations of female entrepreneurship as an individual or gender economic variable, in fact, also pose a theoretical problem at the aggregate level, not just at the company level. This is because at the "corporate level, a decrease in sales prices results in a decrease of the value created. On the contrary, in comparisons in constant prices, this decrease is not measured at macroeconomic level" (Serafini 2014, p. 3090). Moreover, "even if female entrepreneurship is considered a variable that creates value, its contribution can't be measured at an aggregate level since we won't be able to adequately separate a change in price from a change in wealth" (Serafini 2017, p. 957). As a consequence, national accounting systems cannot measure the contribution of entrepreneurship to value creation, due to price variations, accounting rules and theory. We cannot establish whether a price variation for a commodity represents, at the aggregate level, a relative price variation or an increase in wealth inserted into an economic system. In the case of female entrepreneurship, a preceding identification problem emerges, i.e., the previous qualification of what should but cannot be measured. The research into the field of female entrepreneurship, therefore, indicates a path to follow for a more general and methodological reflection on the nature of entrepreneurship in general. This is because the expression of female entrepreneurship itself indicates implied research attention to a super-individual level of analysis of economic variables that directly involves all economic research, not just gender issues.

In conclusion, the individual or collective nature and social or natural classification of female entrepreneurship is, in the literature, only insinuated and not methodologically questioned. This lack of explicit reflection causes various difficulties regarding the definition, classification and measurement of its features, at both the business and aggregate levels. We proposed an identification procedure and a fourfold classification hypothesis with the aim of supporting the future debate on this fundamental issue in business and economics.

Author Contributions: Paola Paoloni provided the literature analysis and Gabriele Serafini specified the female entrepreneurship classification methodology. Both Authors wrote the paper.

Funding: This research received no external funding.

Conflicts of Interest: The authors declare no conflicts of interest.

\section{References}

Barker, Drucilla, and Edith Kuiper. 2003. Towards a Feminist Philosophy of Economics. London and New York: Routledge. Bettio, Francesca, and Alina Verashchagina. 2008. Frontiers in the Economics of Gender. London and New York: Routledge. 
Boniolo, Giovanni, and Paolo Vidali. 2003. Introduzione alla filosofia della scienza. Milano: Mondadori.

Bracalente, Bruno, Massimo Cossignani, and Anna Mulas. 2009. Statistica Aziendale. Milano: McGraw-hill.

Hausman, Daniel M. 2008. The Philosophy of Economics: An Anthology. Cambridge: Cambridge University Press.

Leti, Giuseppe. 1983. Statistica Descrittiva. Bologna: Il Mulino.

Madden, Kirsten. Kara. 2002. Female contribution to Economics. History of Political Economy 34: 1. [CrossRef]

Mitchell, Stephen A. 2014. Relationality. From Attachment to Intersubjectivity. New York: Psychology Press.

Paoloni, Paola, and Paola Demartini. 2016. Women in management: Perspectives on a decade of research (2005-2015). Palgrave Communications. [CrossRef]

Parker, Simon C. 2018. Economics of Entrepreneurship, 2nd ed. Cambridge: Cambridge University Press.

Schumpeter, Joseph A. 1991. History of Economic Analysis. London: Routledge.

Screpanti, Ernesto, and Stefano Zamagni. 2005. An Outline of the History of Economic Thought. Oxford: Oxford University Press.

Serafini, Gabriele. 2014. Intellectual Capital Value Creation and Economic Theories. In Knowledge and Management Models for Sustainable Growth. Edited by Daniela Carlucci, J. C. Spender and Giovannni Schiuma. Matera: Institute for Knowledge Asset Management, pp. 3090-110.

Serafini, Gabriele. 2016. Neoclassical Theory and Female Entrepreneurship as Independent Factor of Production. A Systematic Review of the Economic Models. In Towards a New Architecture of Knowledge: Big Data, Culture and Creativity. Edited by J.C. Spender, Giovanni Schiuma and Jörg Rainer Noennig. Matera: Institute for Knowledge Asset Management, pp. 1918-28.

Serafini, Gabriele. 2017. Business economics vs political economics: Why female entrepreneurship value creation is underestimated at macroeconomic level. In Knowledge Management in the 21th Century: Resilience, Creativity and Co-Creation. Edited by J.C. Spender, Giovanni Schiuma and Jörg Rainer Noennig. Matera: Institute for Knowledge Asset Management, pp. 957-61.

Serafini, Gabriele. 2018. A fourfold classification of Female entrepreneurship concept. In Advances in Gender and Culture Studies in Business and Economics. Edited by Paola Paoloni and Rosa Lombardi. Heidelberg and New York: Springer, in press.

Swedberg, Richard. 2000. Entrepreneurship: The Social Science View. Oxford: Oxford University Press.

Walras, Marie Esprit Léon. 2006. Elementi di economia politica pura. Milano: Milano Finanza Editori, I grandi classici dell'economia, vol. 11. 